\title{
Del Culturalismo al Ciudadanismo
}

\section{From Culturalism to Citizenship}

\author{
Lorenzo Casellas López \\ Psicólogo social
}

Jorge Rocha Cuesta

Catep Intervención Social

Resumen. El artículo plantea el debate entre las miradas culturalista y ciudadanista en al ámbito de los procesos de integración entre la población inmigrante y la autóctona. Se parte de un análisis de la concepción esencialista del término 'cultura', señalando algunos de sus déficits y algunos de los riesgos que supone el manejo de esa concepción; lo cual permitirá entender la cultura como algo más que las costumbres o la esencia de un pueblo. Asimismo se exponen - a la luz del continuo ético universalismo-relativismo- los riesgos de manejar una idea de integración centrada en la cultura, y se ofrece una propuesta de carácter ciudadanista que pretende superar el enfoque culturalista al considerar la integración como multidireccional, procesual y encaminada hacia la equiparación de derechos entre todas las personas.

Palabras clave: cultura, diversidad, inmigración, integración, ciudadanía, diálogo igualitario, integración ciudadana, convivencia.

Summary. This article places the immigrants' integration issue within the culture-citizenship debate. In order to understand culture as something else than people's given customs or "essence", the text begins by analysing the essentialist notion of the term 'culture', pointing out some of its deficiencies and risks involved in dealing with such a notion. Drawing on the ethical relativism-universalism continuum, the authors also discuss the drawbacks they see in a culture-centred integration, suggesting instead a citizenship approach based on a multidirectional and dynamic notion -aimed at achieving equal rights for everyone involved, immigrant and native populations alike.

Key words: culture, diversity, immigration, integration, citizenship, egalitarian dialogue, civic integration, coexistence.

En los últimos años, el concepto de 'cultura' ha jugado un papel central en el análisis de los procesos de integración de las personas inmigrantes en sus sociedades de acogida, y en el diseño de políticas y acciones sociales dirigidas a mejorar dichos procesos. Lejos de albergar un único significado, la idea de 'cultura' esconde diferentes concepciones de las sociedades humanas y de los procesos y sistemas que las conforman. Como consecuencia han aparecido también diferentes modelos de comprensiónacción de y sobre la integración.

La correspondencia sobre este artículo puede dirigirse a los autores a través de los correos electrónicos: lorenzo.casellas.lopez@gmail.com; jorge@catep.coop
En el presente artículo examinamos de forma esquemática dos formas de entender la cultura, partiendo de un análisis crítico de la concepción más esencialista. Nuestra propuesta se alinea con quienes proponen no sólo una superación de esa mirada esencialista, sino el desplazamiento del foco de atención, en los asuntos relacionado con la integración, desde la noción de cultura a la de ciudadanía.

\section{La concepción esencialista del concepto cultura. Un análisis crítico}

La acepción más clásica de 'cultura', y la que se utiliza con más frecuencia, nos remite a las costum- 
bres y al patrimonio de un determinado grupo humano: el conocimiento, las creencias, el arte, la moral, el derecho, las costumbres y cualesquiera otros hábitos y capacidades adquiridos por él. Se trata de una perspectiva que tiende a ver la cultura como propiedad de un grupo, como algo inmutable, ligado a su esencia, a como 'verdaderamente es'.

Esta concepción "deriva del romanticismo alemán, que la utilizó para designar el 'espíritu' de un pueblo determinado. Procede de la convicción de que las naciones estaban dotadas de un alma colectiva, consecuencia de su historia. Las culturas serían totalidades cerradas, que contienen la cosmovisión y el talante de un grupo étnico" (Delgado, 1999).

Analizando esta perspectiva vemos que tiende a ver la cultura como:

- Ligada a la idea de estado-nación. Todas las personas pertenecientes a una misma nación compartirían una manera de ser, de entender la realidad y de actuar.

- Ligada a la esencia de las personas. Quienes pertenecen a una determinada cultura 'la llevan dentro', forma parte de ellos, les define.

- Propiedad de un grupo. Y, por tanto, no debe ser usurpada.

- Inmutable, no cambia. Se mantiene en el mismo estado con el paso del tiempo.

Tomemos la última de las características mencionadas, la supuesta inmutabilidad de la cultura, y analicemos, por ejemplo, la 'cultura española'. ¿Podríamos afirmar que no se han producido cambios en ella a lo largo de los últimos cincuenta años? ¿Esa pretendida esencia ha permanecido inmutable durante este período? ¿Por ejemplo, el tipo de relación que se establece entre las personas que viven en un mismo edificio o en el mismo barrio continúa siendo el mismo? ¿Qué ha ocurrido con la consideración social de las parejas formadas por personas del mismo sexo? ¿Las personas mayores reciben el mismo trato que hace medio siglo? ¿No ha cambiado el protagonismo de la religión en la formación reglada, o los criterios que guían la educación de hijos e hijas?

Este ejemplo, como muchos otros que podrían aportarse, permite ver de una forma rápida y sencilla que resulta extremadamente difícil sostener que una cultura sea algo inmutable. La realidad social, compleja y cambiante, pone en cuestión una definición esencialista de la cultura.

\section{Riesgos de una concepción esencialista de la cultura}

La utilización de una concepción esencialista de la cultura no sólo refleja y provoca una imagen distorsionada de las sociedades humanas. En el ámbito de la intervención psicosocial -y partiendo del análisis realizado por Gregorio y Franzé (1999) - podemos identificar, al menos, cuatro grandes riesgos derivados de este uso:

a) Considerar el origen como única fuente de diversidad.

b) Reducir el individuo a un 'ejemplar' de su cultura.

c) No respetar la libertad intracultural.

d) Utilizar la cultura como argumento de exclusión.

\section{a. Considerar el origen como única fuente de diversidad}

Cuando se sitúan los aspectos culturales en un lugar central en la comprensión de las personas y además se maneja una concepción de ellos como la que hemos descrito más arriba, corremos el riesgo de olvidar que existen muchas otras variables que contribuyen a la conformación de cada persona. Con frecuencia, cuando hablamos de diversidad nos estamos refiriendo a la diversidad de origen de las personas: dónde han nacido, de dónde vienen; y cuando intentamos explicar por qué una persona se comporta o piensa de esta o aquella manera atribuimos un peso excesivo a 'su cultura' - entendiendo 'su cultura' como la de su país de origen - ¿AAcaso las personas se diferencian unas de otras sólo por el lugar del que proceden? ¿No existen diferencias de índole económico, educativo, social, de género, de prácticas sexuales, de aspecto físico, de gustos, de intereses...?

Como afirma Delgado (1999), existen otros "principios de adscripción que, para muchos, tienen un valor superior a lo estrictamente étnico. La inclusión en un género sexual, en una generación o en 
una clase social son algunos ejemplos. Los apellidos hacen que cada uno sea pariente; el lugar de nacimiento le hace paisano; las ideas políticas o religiosas, correligionario; el barrio donde vive, vecino; la edad, coetáneo. Los gustos musicales o literarios, el estilo de vestir, las aficiones deportivas, el lugar donde estudia o estudió de joven, los temas de interés, etc.; cada uno de estos elementos instala a cada individuo en el seno de un conglomerado humano constituido por todos los que lo comparten y que, a partir de él, pueden reconocerse y sentirse vinculados por sentimientos, orígenes, orientaciones o experiencias comunes".

\section{b. Reducir el individuo a un 'ejemplar' de su cultura}

Cuando nuestra mirada está dominada por una concepción esencialista de la cultura corremos el riesgo de "atribuir a las personas unos rasgos abstraídos, impidiendo el verdadero conocimiento de sus circunstancias" (Franzé, Casellas y Gregorio, 1999), negando la individualidad de cada persona. Entendemos entonces que si una persona 'pertenece' a una determinada cultura se debe comportar de una determinada manera.

Si entramos en contacto con una persona de un país determinado - del que probablemente desconocemos toda la complejidad que lo conformareduciremos nuestra idea sobre ella al conjunto de estereotipos que asociamos a su correspondiente cultura. Lo que le ocurre a esa persona a nivel individual, sus opciones personales o el valor que tienen para ella determinadas prácticas influirán poco en nuestra percepción, ya que lo que la define es la cultura a la que pertenece. La cultura sería, entonces, una especie de compartimiento estanco dentro del cual están las personas que supuestamente pertenecen a ella y del que no permitimos que puedan salir.

Esta forma de entender la cultura nos ayuda a categorizar rápidamente a las personas, pero si atendemos a nuestra experiencia es fácil caer en la cuenta de que entre personas concretas de un determinado grupo cultural existen diferencias significativas.

Propongámonos un breve ejercicio. Elaboremos un listado de las características que, según creemos, caracterizan 'la cultura' de nuestro país. Compro- bemos después si nosotros mismos nos identificamos con dichas características. Seguramente descubriríamos que no, que si bien recurrimos con suma facilidad a utilizar las características que hemos señalado como descriptores de una cultura para describir a otra persona, difícilmente estaríamos dispuestos a hacer eso con nosotros mismos. Sin ser conscientes de ello nos autoatribuimos una mayor complejidad que a los demás.

Otro ejemplo que puede ayudar a entender este riesgo de manejar una visión esencialista de la cultura son las llamadas fiestas interculturales que se desarrollan, por ejemplo, en muchos centros educativos. Por lo general, se reserva un día a visibilizar las diferencias entre las personas de distintos orígenes. Nos dedicamos a fijarnos en cómo son los demás, en lo diferentes que somos, en estereotiparles a través de manifestaciones culturales como el folclore o la gastronomía. La comida se la encargamos a las chicas de origen marroquí porque, siendo chicas y marroquíes, es indudable que cocinarán un exquisito couscous para deleite de nuestros paladares; a los chicos, que toquen los timbales o que canten canciones típicas. Aunque nunca utilicen la vestimenta tradicional de su lugar de origen les pediremos a todos y todas, que vengan vestidos con los trajes típicos... ¿Qué pensaríamos si nos trasladamos a vivir a otro país y desde el nuevo centro escolar de nuestras hijas nos piden algo similar? Lo que estamos haciendo es remarcar la diferencia. Poner el énfasis en lo diferentes que somos obliga a las personas a comportarse como nosotros creemos que se comportan, como marca el estereotipo que tenemos formado de ellas como pertenecientes a determinada cultura.

Como afirma Delgado (2007), "estas fiestas se convierten en un escaparate y en una forma de obligar a las personas a hacer cosas que es probable que no encajen en su identidad individual, pero que es lo único que consideramos que pueden hacer [...] Estas fiestas de la diversidad se convierten en mecanismo para encontrar y señalar al diferente. $Y$ no sólo para eso, sino para exigirle algo que nosotros no haríamos, dar explicaciones de lo que es (o de lo que nosotros pensamos que es)". Y aún con mayor contundencia se expresa en una entrevista El Hachmi (Navarro, 2007): "Creo que los rasgos más 
o menos étnicos están bien, pero no hay que reivindicarlos. No hay que quedarse en la fiesta multicultural, que obliga a demostrar la tolerancia. Yo a eso lo he bautizado con un término: ¡Pornografía étnica! Hay quien la ejerce, incluso con buena voluntad, pero hace mucho daño. Los pornógrafos de la etnicidad acentúan rasgos de ti que en tu país encontrarías ridículos. Se quedan con el folclore."

\section{c. No respetar la libertad intracultural}

Con frecuencia hablamos de la diversidad cultural en nuestras sociedades. Cuando manejamos una concepción esencialista de cultura nuestra mirada se centra en el hecho de que existen grupos sociales con diferentes características y prácticas que coexisten y que, según nuestra forma de entender la integración, deberían aprender a coexistir, adaptarse a las del grupo dominante o fundirse en una nueva forma cultural mestiza.

Sin embargo, esta mirada nos hace ver como homogéneas a las personas que pertenecen a un mismo grupo, ignorando que dentro de cada uno de esos grupos culturales existe también una enorme diversidad de opciones personales y de formas de vida. Esta concepción niega la diversidad hacia el interior de los grupos culturales, asumiendo que el lugar en el que se vive o el grupo al que se pertenece exige unos modos de pensar y de comportarse acotados dentro de unos márgenes muy estrechos.

El concepto de "libertad cultural", desarrollado ampliamente en el informe anual del año 2004 del Plan de las Naciones Unidas para el Desarrollo (PNUD, 2004), es utilizado para señalar que es preciso que en el seno de un determinado grupo puedan tener cabida diferentes formas de vida: no puede considerarse un avance en términos de desarrollo humano la mera preservación de las formas de vida de una determinada comunidad, si en su seno no se acepta la posibilidad de disentir, de elegir opciones diferentes a las de la mayoría o a las del grupo dominante.

Ignorar la diversidad intrínseca a cada sistema cultural supone negar la libertad cultural. Así, el respeto y reconocimiento de las diferentes culturas debe llevar aparejada el respeto a la libertad de cada individuo de elegir sus propias formas de vida.
Nacer o vivir en el seno de una cultura no debe suponer tener que amoldarse a ella, puesto que las personas no son el soporte de la cultura, sino las creadoras de la misma.

"La libertad no se puede disociar de la oportunidad de elegir o al menos de poder considerar la forma de ejercer una opción si ésta estuviera disponible. El aspecto medular de la libertad cultural es la capacidad de las personas de vivir como desearían hacerlo y de contar con oportunidades aceptables para evaluar otras opciones" (PNUD, 2004).

La siguiente frase de Gandhi (1921) resume a la perfección el interés del concepto de libertad cultural: "No quiero mi casa amurallada por todos lados ni mis ventanas selladas. Yo quiero que las culturas de todo el mundo soplen sobre mi hogar tan libremente como sea posible, pero me niego a ser barrido por ninguna de ellas".

\section{d. Utilizar la cultura como argumento de exclusión}

Hoy en día son minoritarios los discursos que incluyen el concepto de raza y mucho más aún los que afirma que existen razas inferiores y superiores: dichas afirmaciones quedan completamente al margen de lo políticamente correcto. Sin embargo, algunos usos del concepto de cultura - en especial aquellos que la entienden como esencial, homogénea y estática - parecen limitarse a sustituir una palabra por otra - raza por cultura - manteniendo el mismo tipo de argumentaciones ${ }^{2}$.

En esta línea, la Declaración del X Congreso de Antropología de la Federación de Asociaciones de Antropología del Estado Español advertía de que "la cultura se ha convertido hoy en un mero sucedáneo de la desprestigiada idea de raza y sirve, mucho más sutilmente, para lo mismos fines, que no son otros que los de la naturalización de las asimetrías sociales y la justificación ideológica de la exclusión social. [...] Donde un día se habló de 'razas inferiores' se habla ahora de culturas 'incompatibles con nuestros valores'. [...] Los medios de comunicación emplean una y otra vez la noción de cultura para trivializar y simplificar determinados conflictos socia-

2 Esta idea ha sido magníficamente analizada por Stolcke (1999) al describir lo que ella denomina "fundamentalismo cultural". 
les, insinuando que sus causas tienen que ver oscuramente con las adhesiones culturales de sus protagonistas." (FAAEE, 2003)

A pesar de que desde los códigos deontológicos del periodismo se "desaconseja su uso [nombrar la nacionalidad de los implicados en sucesos delictivos] porque este tipo de informaciones implican formas periodísticas más o menos veladas de racismo implícito e institucional" (Villalobos, 2003), basta una rápida mirada a los medios de comunicación españoles para comprobar que esa práctica es bastante frecuente. Así, las noticias de robos, estafas, tráfico de drogas, peleas, asesinatos, etc. suelen ir acompañadas de la nacionalidad de sus autores, siempre que estos sean extranjeros. Esta práctica ayuda a formar una asociación mental entre delincuencia y extranjería - o más concretamente entre delincuencia e inmigración-, que acaba generando la percepción social de que la causa de que alguien cometa un acto delictivo es su condición de extranjero o inmigrante.

Y no sólo ocurre con los medios, desde los últimos meses del año 2008 estamos asistiendo en la Comunidad de Madrid a una auténtica persecución a los inmigrantes sin documentación, a través de identificaciones indiscriminadas a aquellas personas que fenotípicamente parecen diferentes. De nuevo la misma asociación: delincuencia-inmigración.

En última instancia, como afirma Pajares (2005), "la etnicidad ha servido para crear una diferencia esencial, una distancia, que impide a 'los diferentes' integrarse plenamente en los sistemas sociales que los permitirían salir del rol y las condiciones reservadas para ellos; $y$, aunque de modo individual, una parte de ellos acaban saliendo, otros muchos quedan atrapados en este sistema diferencial que relaciona etnicidad con rol social".

\section{Otras formas de entender la cultura}

Entonces, ¿cómo enfrentar los riesgos de utilizar una concepción esencialista de la cultura?

La mencionada declaración del X Congreso de la FAAEE nos recuerda que "la acuñación del concepto de cultura desde la Antropología quiso contribuir a desautorizar científicamente la pretensión de que existía algún fundamento 'racial' en la variedad de formas humanas de pensar, hacer y decir y mucho menos en su calificación como 'superiores' o 'inferiores'. El origen de la heterogeneidad humana quedaba instalado, de la mano de esa noción de cultura - como entidad cambiante, dinámica, determinante, pero también determinada por la historia - en la capacidad de los seres humanos no sólo de vivir en sociedad, sino de generar y transformar constantemente la sociedad en que vivían" (FAAEE, 2003).

Esta forma de entender la cultura de un grupo humano presta atención al entramado de valores, significados y códigos que dicho grupo elabora para responder a sus necesidades, para interpretar la realidad y para que sus miembros se relacionen entre sí. La cultura de un grupo estaría conformada por las formas de hacer, decir y pensar presentes en él; por el conjunto de interacciones y relaciones sociales que se dan en su seno; o, más vagamente, por todo aquello que el grupo produce simbólicamente.

Desde esta perspectiva podríamos definir cultura como el conjunto de prácticas y relaciones - materiales y simbólicas - producidas de forma continuada por un grupo humano, y que están entrecruzadas por heterogeneidades, asimetrías y tensiones económicas, sociales y políticas. Como, en línea con este planteamiento, se afirma en el Informe de Desarrollo Humano de 2004: la cultura "no es un conjunto estático de valores y prácticas. Se recrea constantemente en la medida en que las personas cuestionan, adaptan y redefinen sus valores y prácticas ante el cambio de la realidad y el intercambio de ideas" (PNUD, 2004).

Podemos, pues, identificar tres características básicas de esta forma de entender la cultura, que se contraponen a las de la concepción esencialista:

- Toda cultura es construida por los seres humanos de un grupo a lo largo de la historia; no es algo propio de una supuesta esencia del grupo.

- Toda cultura es dinámica, está en permanente cambio, es recreada constantemente por las personas del grupo, sin que exista una delimitación cerrada y estática.

- Toda cultura es heterogénea; en su interior tiene cabida la diversidad. Por un lado porque en una misma cultura están englobadas diferentes manifestaciones culturales - de alguna manera 
todas las culturas son interculturales ${ }^{3}-$, y por otro porque existen tantas concreciones de la misma como subjetividades conforman el grupo cultural de referencia. Como nos recuerda Cobo (2006), la aparente homogeneidad es sencillamente el producto de los diversos sistemas de dominación que atraviesan cualquier sistema cultural, que subordinan unas formas de vida a otras.

\section{La convivencia entre culturas: relativismo y universalismo}

Una vez aclarado el concepto de cultura que manejamos, sería el momento de acometer el análisis de cómo entendemos e intervenimos sobre los procesos de integración entre personas procedentes de sistemas culturales diferentes. Obviamente, puesto que hemos asumido que toda cultura es intercultural, partimos del hecho de que estos procesos de integración son algo consustancial a cualquier grupo social, no sólo es algo propio de las sociedades a las que llega población inmigrante. La llegada de un número elevado de personas de otros lugares no hace sino poner más claramente de manifiesto la necesidad de construir un marco de convivencia en el que tienen cabida diferentes formas de vida. Insistimos: ese proceso se da, de una manera u otra en cualquier sociedad, si bien es cierto que se hace más visible cuando a un grupo social se incorpora un número importante de personas ajenas a él $\mathrm{y}$, especialmente, si eso ocurre en un lapso de tiempo corto.

Para analizar esos procesos de integración será útil detenernos previamente en dos conceptos que están en la base de la mayoría de los modos de entender la integración: universalismo y relativismo. No se pretende en este artículo analizar de forma exhaustiva dichos conceptos, sino presentarlos de una forma sencilla para poder establecer la relación entre las formas de ver el mundo que cada uno de ellos representa y las formas de entender los procesos de integración. En realidad se trata más de presentar los dos polos de un continuo de posiciones éticas en el que cualquier profesional dedicado a la

${ }^{3}$ En esta línea puede consultarse el trabajo de Cabezas (2007). intervención psicosocial puede intentar ubicar sus propios planteamientos.

Desde la postura del universalismo se entiende que existen algunos valores morales superiores a otros y que son y deben ser aceptados por todos los seres humanos, independientemente del grupo social al que pertenecen. Esta forma de ver el mundo garantizaría la posibilidad de convivir en armonía y con el necesario grado de cohesión social.

Desde la postura del relativismo, por el contrario, se entiende que existen diferentes valores morales y ninguno de ellos está por encima de los demás, todos son válidos: no hay forma de demostrar la superioridad de unos sobre otros. "La bondad de unos valores y actitudes morales depende de la comunidad específica en la que surgen y no de criterios independientes y generales que sobrepasan la frontera de esa comunidad. [...] Ningún código moral es superior a otro o, al menos, nadie puede demostrar que así sea" (Giner, 1997). Esta forma de ver el mundo garantizaría el respeto a las diferentes formas de vida.

Ambas concepciones llevadas al extremo suponen una serie de riesgos para la convivencia. Analizarlos servirá para discriminarlos de los elementos de ambas posiciones que pueden ser aprovechados para crear un modelo satisfactorio de convivencia entre diferentes formas de vida o, como venimos diciendo hasta ahora, culturas.

\section{Universalismo. Riesgos para la convivencia}

El primer riesgo que suponen las posturas universalistas extremas se deriva de la siguiente cuestión: si existen unos valores superiores, ¿cuáles son y, sobre todo, quiénes y cómo lo deciden? La historia nos muestra que la respuesta a esa pregunta está en las dinámicas de dominación e imposición que han guiado las relaciones entre los grupos humanos: los valores universales son aquellos de los grupos más poderosos, que los imponen a los demás.

El segundo riesgo derivado de las posiciones universalistas es la invisibilización de las formas de vida que no son coherentes con los valores dominantes. En un contexto de estas características se interpretan las diferencias con el modelo dominante 
como desviaciones de lo correcto, como algo negativo, puesto que ponen en peligro la necesaria cohesión social. Se produce, por tanto, una tendencia a la uniformización que dificulta la libre elección de valores, actitudes y comportamientos.

Como tercer riesgo asociado a un universalismo extremo nos encontramos con que dichas posturas, más allá de percibir los disensos internos como peligrosos, perciben también como amenazantes a otros grupos con otros valores. La dominación interna se intenta reproducir hacia fuera del grupo, bajo la supuesta premisa de que aquello que resulta válido en el seno del propio sistema cultural debe serlo también fuera de él. Aparecen así posturas etnocentristas, que consideran los sistemas de valores de otros grupos culturales como inferiores.

El último riesgo asociado al universalismo es que lleva a entender la integración entre dos grupos culturales - por ejemplo, entre la población autóctona y la alóctona de un determinado territorio- como algo unidireccional ${ }^{4}$. Los grupos minoritarios $-\mathrm{O}$ recién llegados - son los únicos que deben realizar un esfuerzo de adaptación, puesto que provienen de un sistema cultural inferior que necesariamente está obligado a evolucionar hacia las formas de vida del grupo dominante.

\section{Relativismo. Riesgos para la convivencia}

El primer riesgo para la convivencia que presentan las posturas relativistas nace de la dificultad de llevar hasta sus últimas consecuencias la aceptación de cualesquiera sistemas de valores como igualmente válidos $\mathrm{y}$, de nuevo, de la tendencia a la imposición de sus propios valores que ejercerán los grupos dominantes. A muchas personas, por ejemplo, les resultaría difícil aceptar como válido un sistema de valores que acepte el sometimiento de unas personas a otras dentro de un grupo social, por mucho que dicha práctica sea la elegida por dicho grupo. Además, en el seno de un contexto social donde prevaleciesen los postulados relativistas seguiría dándose con toda probabilidad el mismo

${ }^{4}$ Desarrollaremos más adelante las características de las diferentes formas de entender la integración. juego de poder que, en un contexto universalista, llevan a los grupos dominantes a imponer sus valores y formas de vida.

El segundo riesgo del relativismo es la generación de un escenario en el que la segregación y la creación de guetos son prácticas habituales. Puesto que dos o más sistemas culturales no pueden entrar en diálogo para dilucidar qué valores son más convenientes, lo mejor es mantener esos grupos separados entre sí para que cada uno de ellos pueda desplegar completamente sus formas de vida. Desde esta premisa será extremadamente difícil abordar la construcción conjunta de un escenario de convivencia.

Para terminar, un tercer riesgo del relativismo llevado al extremo es acabar confundiendo diferencia con desigualdad. Si en un contexto de talante relativista existen desigualdades, éstas podrán atribuirse a las características intrínsecas de los grupos más desfavorecidos: serían sus prácticas culturales las que les estarían colocando en esa situación. La desigualdad, por tanto, sería parte de la condición humana y no el fruto de los sistemas de dominación que atraviesan los grupos sociales. Para comprender mejor este riesgo podemos apoyarnos en los análisis feministas que nos han enseñado a reconocer esta dinámica perversa del binomio diferencia-desigualdad, mostrando cómo las desigualdades existentes entre mujeres y hombres se han apoyado tradicionalmente en la percepción de diferencias entre las personas de ambos sexos.

\section{Uniendo relativismo y universalismo}

Hasta ahora hemos centrado la atención en los riesgos de las interpretaciones más estrictas de las perspectivas universalista y relativista, pero ambas formas de entender los valores contienen aportaciones que se pueden combinar en la búsqueda de la mejora de la convivencia entre diferentes culturas.

Por un lado, parece razonable la propuesta universalista de que exista un cierto consenso sobre las normas que rigen un grupo social; unas normas válidas para todas las personas facilitarán la regulación 
de los conflictos en el seno del grupo. Por otro lado, parece igualmente razonable la propuesta relativista de que es ineludible la expresión de las diferencias dentro de un grupo social; esto permite un desarrollo más pleno de los grupos y las personas y, en última instancia, los enriquece puesto que les ofrece más posibilidades de opción.

¿Cómo hacer compatibles ambas tendencias? Dos son las ideas principales que podrían guiar la respuesta a esta pregunta: el consenso sobre las normas comunes debería limitarse a algunas cuestiones centrales, a unos mínimos compartidos; y el criterio de validez de las normas comunes debería ser el procedimiento utilizado para seleccionarlas.

Reducir el consenso sobre normas y valores a unos mínimos compartidos puede permitir "la lealtad a un sistema normativo que hará posible que coexistan, simultáneamente, lealtades diferentes" (Flecha, 2005). La expresión de diferentes formas de vida dispondrá de un amplio margen si el empeño en consensuar normas no invade un espectro demasiado amplio de cuestiones. Aún así, la búsqueda de esos mínimos normativos no deja de ser un ejercicio complicado, puesto que pueden surgir obstáculos referidos a quiénes los seleccionan, en base a qué criterios y de qué forma lo hacen.

Cobra entonces importancia la idea de ubicar el criterio de validez de una norma en el procedimiento por el que ésta se adopta. Esto es, serán válidas aquellas normas que estén seleccionadas porque existe acuerdo en que son las mejores. Desde la ética dialógica - también denominada comunicativa, discursiva o procedimental - la idea se formula así: "Una norma sólo será correcta si todos los afectados por ella están dispuestos a darle su consentimiento tras un diálogo, celebrado en condiciones de simetría, porque les convencen las razones que se aportan en el seno del mismo diálogo" (Cortina, 2004).

Dicho diálogo debería tener unas características peculiares, que exponemos a continuación siguiendo la propuesta de Habermas (1999):

- Es necesaria la participación de todas las personas afectadas o interesadas. Un diálogo en el que no participan todas las personas supone que, incluso aunque se esté de acuerdo con las decisiones tomadas, al no haber participado en el debate no se reconozca el resultado.
- Todas las personas deben disponer de igualdad de oportunidades para aportar argumentos al diálogo.

- Debe haber ausencia de coacciones, tanto internas como externas, en la comunicación.

- Todas las personas, además de estar presentes, deben aportar al diálogo, ninguna voz debe silenciarse, y todas deben enunciar sus propuestas. Deben existir tiempo y mecanismos para que todas participen.

- Lo importante son los argumentos que se ponen sobre la mesa y no quién los aporta, es decir, los argumentos están por encima de las personas que los plantean. Éstos no tienen por qué ser siempre extraordinariamente racionales y ordenados, también son válidos argumentos más emocionales ${ }^{5}$.

Evidentemente, todas estas condiciones convierten la propuesta dialógica en una tendencia, ya que es imposible cumplirlas en términos absolutos. Lo fundamental será, pues, establecer mecanismos para que en un grupo humano todas las personas tengan las oportunidades más equilibradas posibles para participar. Por otro lado, también parece claro que una propuesta de estas características es más sencilla de llevar adelante cuanto más pequeño sea el grupo. Los contextos en los que suele desarrollarse la intervención psicosocial (familia, grupo, aula, centro educativo, asociación, centro de trabajo, barrio, municipios) pueden considerarse grupos relativamente pequeños, por lo que son especialmente indicados para poner en práctica la propuesta dialógica.

\section{La convivencia entre culturas: integración}

Una vez analizados los conceptos de universalismo y relativismo, estamos en condiciones de prestar atención a las diferentes formas de entender la integración que han ido apareciendo a lo largo del siglo $\mathrm{XX}$ en las sociedades a las que se ha incorporado población migrante ${ }^{6}$.

\footnotetext{
5 Sobre la gestión eficiente de los diferentes aspectos que entran en juego en el diálogo en un grupo puede consultarse el trabajo de De Bono (1997).

${ }^{6}$ Para un análisis más detallado de los diferentes modelos puede consultarse el trabajo de Garreta (2003).
} 
No es intención de este artículo profundizar en cada uno de los modelos de integración, sino señalar alguno de los elementos clave que los configuran de manera que sea posible identificar los modelos subyacentes a las prácticas de acción social en materia de integración. No obstante, debe tenerse en cuenta que, en la actualidad, las políticas y líneas de intervención que se desarrollan en cada territorio suelen contener una combinación de elementos de diferentes modelos.

Dejando al margen la propuesta que podría denominarse exclusionista - que no reconoce la igualdad de quienes proceden de fuera de un determinado territorio-, éstas podrían ser las principales aportaciones de cada modelo:

- Asimilacionista. Este modelo propugna la no discriminación en función del origen, siempre que cada persona adopte como valores y formas de vida los valores ya existentes en la sociedad a la que llega.

- Multiculturalista. Este modelo reconoce la existencia y los derechos de cada una de las comunidades que conforman un grupo social, con sus diferentes formas de vida, independientemente de que sean autóctonas o no del correspondiente territorio y de su carácter o no de grupo social dominante.

- Interculturalista. Este modelo añade al multiculturalista la propuesta de que los diferentes grupos culturales deben entrar en relación entre sí.

- De diversidad. Desde el modelo de la gestión de la diversidad se plantea que el origen de las personas es sólo una diferencia más de las muchas que atraviesan un grupo social. Asume que en cualquier grupo social coexisten diferentes formas de vida y que las actuaciones de los poderes públicos deben adaptarse a ellas, sea cual sea la dimensión que está en la base de la diferencia (sexo-género, edad, capacidad, origen, prácticas sexuales, etc.).

- Ciudadanista. Para este modelo la clave está en la construcción colectiva en términos de igualdad. No se trata sólo de que existan diferentes formas de vida, ni de que estas tengan que relacionarse sin más, sino de que todas las personas que comparten un territorio participen activamente en él.

\section{Críticas a los enfoques culturalistas de la integración}

Para continuar profundizando en el análisis y la propuesta que plantea este artículo, podemos distinguir, de entre los cinco modelos mencionados, tres que podríamos denominar culturalistas: los tres primeros. En ellos, la mirada sobre la integración toma como referencia la cultura de los diferentes grupos y comunidades que conforman una sociedad.

Las insuficiencias de los modelos culturalistas pueden agruparse en torno a las siguientes tres críticas, en parte basadas en cuestiones ya expuestas en los primeros apartados de este artículo, y ligadas fundamentalmente a las concepciones de cultura más esencialistas.

La primera crítica que surge es que si nos centramos en la cultura al hablar de integración estamos reforzando los límites entre los grupos culturales. La constatación permanente de la diferencia no es necesariamente útil en términos de integración. Si prestamos constantemente atención a aquello que nos separa en función de nuestras culturas, lo que probablemente conseguiremos es hacer más sólidas esas diferencias y dificultar el encuentro constructivo. A la vez, estamos ignorando tanto lo que nos une como seres humanos, como nuestros intereses comunes como habitantes de un mismo espacio de convivencia. Como dice Touraine (2005), "la integración sólo tiene sentido si está totalmente asociada al reconocimiento del Otro no en su diferencia, sino en su igualdad conmigo mismo".

La segunda crítica, es que centrarnos en las discriminaciones por motivos de origen nos hace olvidar otras discriminaciones, que se entrecruzan con aquéllas o que incluso se enmascaran debajo de las mismas. Por ejemplo, en al ámbito del feminismo se ha investigado con profusión la triple discriminación por razón de género, etnia y clase ${ }^{7}$. Y estas otras discriminaciones, fruto del entrecruzamiento de diferentes sistemas de dominación, no sólo se olvidan en el marco global de una sociedad, sino en el seno de cada grupo cultural, anteponiendo el respeto a la diversidad cultural a la libertad cultural (PNUD, 2004).

${ }^{7}$ El trabajo pionero de esta línea de reflexión fue el de Morokvasic (1984). 
En tercer y último lugar, los enfoques culturalistas de la integración vacían de contenido las relaciones entre grupos culturales, o al menos lo limitan, forzando a un encuentro que queda restringido en múltiples ocasiones a la exhibición y la reivindicación de la diferencia - recuérdese el ejemplo citado más arriba de las fiestas interculturales-. Con ello se ignora la posibilidad de generar una identidad colectiva a partir de la recreación conjunta y permanente del propio espacio de convivencia en el que todas y todos los habitantes de un territorio están implicados.

\section{La propuesta ciudadanista de integración}

La forma de concebir la integración que proponen los enfoques ciudadanistas consta de tres ideasclave:

- la integración es multidireccional,

- la integración es un proceso,

- la integración pasa por una participación igualitaria el territorio.

Como primera idea clave, la propuesta ciudadanista postula la bidireccionalidad de la integración, frente a otras perspectivas - principalmente las asimilacionistas - que consideran la integración como unidireccional - es decir, que son las personas que llegan como migrantes las únicas que tienen que adaptarse-. Sería ingenuo y poco ajustado a la experiencia histórica pensar que cuando un número significativo de personas se incorpora a un determinado grupo social puede darse el caso de que simplemente se adapten a lo que hay. Ineludible y necesariamente la incorporación de nuevas personas con sus formas de vida y sus formas de entender el mundo provoca adaptaciones y cambios en la 'sociedad de acogida'. Hablaremos entonces de que se produce una adaptación mutua, es decir, se dan cambios en todas y cada una de las partes, y todas necesitan realizar un esfuerzo en ese sentido.

Los propios documentos oficiales de la Unión Europea han recogido en múltiples ocasiones este enfoque. Así, por ejemplo, uno de los principios para las políticas de integración de los inmigrantes aprobados por el Consejo de la Unión en 2004 definen la integración como un "proceso bidireccional y dinámico de ajuste mutuo por parte de todos los inmigrantes y residentes de los estados miembros" (UE, 2004).

En realidad, podríamos hablar de multidireccionalidad puesto que en una misma sociedad coexisten - como ya hemos visto reiteradamente a lo largo del artículo- múltiples formas de vida; muchas de las cuales, además, se dan en el seno de cada uno de los pretendidamente homogéneos grupos culturales que solemos identificar con las personas de una determinada nacionalidad.

La segunda idea-clave es que la integración es un proceso que se da de forma continuada. A cualquier grupo social se incorporan permanente nuevas personas, y no es esto una cuestión sólo de movimientos migratorios. El propio relevo generacional en cualquier comunidad suele conllevar también una tensión dialéctica entre las tendencias a conservar y cambiar las formas de vida. Y cada individuo en sí mismo modifica sus valores, sus actitudes, sus comportamientos a lo largo de su ciclo vital.

Así, "los modelos de integración de los inmigrantes no son separables de los modelos de integración de la ciudadanía en el contexto en el que se están estudiando. Quien piense que se puede tratar, planificar y gestionar la integración de los inmigrantes sin tratar de analizar cuál es el modelo de integración de la ciudadanía está condenado al fracaso" (Martín, 2007).

Este complejo entramado de renovación hace imposible que se pueda entender la integración como algo que se ha producido, sí o no -como si se tratase de un interruptor con dos únicas posiciones- . Por el contrario, resulta inevitable reconocerla como un "proceso social dinámico, prolongado en el tiempo, que tiene que ser continuamente reproducido y renovado" (MTAS, 2007).

Por otro lado, si quisiéramos valorar en términos de sí o no la integración de una persona o de un grupo - para poder dilucidar si ha alcanzado ese estado- debería existir un acuerdo pleno en la identificación de aquello en lo que las personas inmigrantes tienen que integrarse. La realidad es clara en este sentido: aunque sea posible encontrar regularidades compartidas, en cualquier sociedad podemos encontrar diferentes planteamientos éticos y formas de vida. Y esto ocurre más aún en las sociedades 
postindustriales, en las que con frecuencia hay serias dificultades para reconocer la existencia de valores compartidos

Pongamos un breve ejemplo de esto. Podríamos sentirnos tentados de afirmar que las personas llegadas de fuera de nuestras fronteras tienen que adaptarse a nuestro forma de concebir la salud. Se supondría entonces que existe un modo homogéneo y compartido de entender la salud y su cuidado, quizás representado por la medicina alopática del sistema de salud público. Sin embargo, cuántas personas conocemos que utilizan otro tipos de terapias alternativas, que se basan en una concepción completamente distinta de la salud e incluso de la propia persona: naturopatía, acupuntura, yoga, etc. ¿Es realmente cierto que exista una forma consensuada y homogénea de entender la salud, por ejemplo, en nuestra sociedad? ${ }^{8}$ ¿A qué es a lo que tienen que integrarse, pues, las personas que llegan desde otras sociedades? Como afirman Entzinger y Biezeveld (2003): "Todas las sociedades europeas eran culturalmente pluriformes desde mucho antes de que la inmigración a gran escala comenzase".

Entonces, cuál es la propuesta ciudadanista, ¿en qué hay que integrarse? Lo importante para la propuesta ciudadanista $-\mathrm{y}$ esta es la tercera de las ideas-clave que mencionábamos al inicio del apartado-, es que no considera pertinente esta pregunta. Por el contrario, plantea que la integración sólo puede producirse en un contexto de equiparación de los derechos, oportunidades y trato de todas las personas (Pajares, 2005). La integración se da cuando las personas se sientan activas y participes de la vida política, económica, social y cultural.

\section{Síntesis de la propuesta ciudadanista}

Se ha formulado ya cual es la propuesta de la perspectiva ciudadanista y cómo esta pretende superar los déficits y riesgos de los planteamientos culturalistas.

Debería haber quedado claro también que la propuesta ciudadanista no niega la existencia de la cultura, ni el papel central de este concepto para la

\footnotetext{
${ }^{8}$ Un análisis especialmente interesante de este asunto es el realiza-
} do por Uribe (2007). comprensión de las sociedades humanas. La propuesta ciudadanista asume una concepción de la cultura - tal y como se expuso más arriba en este artículo- como algo construido, dinámico y heterogéneo. La propuesta ciudadanista desplaza el foco de atención de las culturas de los grupos que conforman una sociedad a la construcción colectiva entre todas las personas que conviven en un territorio.

En síntesis, estas serían las características principales de los dos enfoques 9 :

\begin{tabular}{cc}
\hline ENFOQUE CULTURALISTA & ENFOQUE CIUDADANISTA \\
\hline Hincapié en la diferencia & Hincapié en la igualdad en la diversidad \\
Relaciones entre culturas & Construcción de proyectos comunes \\
Promoción de colectivos etno-nacionales & Promoción de proyectos ciudadanos \\
Culturalismo esencialista & Identidades dinámicas y múltiples \\
Diversidad cultural & Libertad cultural \\
Alienta la frontera ellos-nosotros & Genera ciudadanía cohesionada \\
Atención específica a población inmigrante & Adaptación de servicios de carácter generalista \\
\hline
\end{tabular}

Aunque está implícito en el discurso mantenido hasta ahora cuál es la noción de ciudadanía que se está manejando en este artículo, parece oportuno cerrar este trabajo exponiendo sus principales características, máxime cuando el término ciudadanía viene siendo utilizado con distintas acepciones en la literatura de las ciencias sociales.

La concepción clásica de la ciudadanía dice que es ciudadano o ciudadana una persona que puede elegir a sus gobernantes y tiene garantizados una serie de derechos. Siguiendo este criterio sólo son ciudadanos de pleno derecho quienes son nacionales de cada país. Incluso el Tratado de Lisboa, que pretende sustituir a la fallida Constitución Europea, dice en su artículo 8: "Será ciudadano de la Unión toda persona que tenga la nacionalidad de un Estado miembro. La ciudadanía de la Unión se añade a la ciudadanía nacional sin sustituirla".

Una mirada crítica a esta concepción de ciudadanía observaría que "la ciudadanía de nuestros países ricos representa el último privilegio de estatus, el último factor de exclusión y discriminación entre las personas en contra de la proclamada universalidad e igualdad de los derechos fundamentales" (Zubero, 2005). Así, se da la paradoja de que personas que participan en el entramado económico de un país -

\footnotetext{
${ }^{9}$ Para ver un desarrollo más extenso del tema que nos ocupa puede consultarse el trabajo de Catep y Sembla (2006).
} 
trabajando, pagando sus impuestos - son excluidos de la participación política, convirtiéndose en ciudadanas 'de segunda'. Hoy por hoy, como decíamos, la ciudadanía plena - entendida como acceso pleno a ciertos derechos - sólo se adquiere mediante la nacionalización.

En este contexto la extensión de la ciudadanía a las personas inmigrantes pasa por dos opciones: o se facilita su nacionalización, o se plantea "que la equiparación de derechos se desarrolle también sobre la base de la residencia, es decir, que los derechos básicos también puedan equipararse sin necesidad de que las personas inmigradas adquieran la nacionalidad" (Pajares, 2005).

Este asunto no sólo ha generado una importante producción académica y política, sino que ha dado lugar a la gestación de un nuevo concepto en el seno de la Unión Europea: 'ciudadanía cívica' —en inglés, civic citizenship - . Aparece por primera vez en el año 2000 en la Comunicación de la Comisión al Consejo y al Parlamento Europeo sobre una política comunitaria de migración, y en ella se plantea un horizonte - sin plazos establecidos - en el que "el estatuto jurídico concedido a los nacionales de terceros países se basaría en el principio de proporcionar conjuntos de derechos y responsabilidades sobre una base de igualdad con los nacionales, pero diferenciados en función de la duración de la estancia, previendo al mismo tiempo la progresión hacia un estatuto permanente. A más largo plazo, esto podría ampliarse hasta el ofrecimiento de una forma de ciudadanía cívica, basada en el Tratado CE e inspirada por la Carta de derechos fundamentales, consistente en un conjunto de derechos y obligaciones ofrecidos a los nacionales de terceros países" (UE, 2000). Se trataría, como se ve, de una especie de estadio intermedio entre la condición de inmigrante (no ciudadano) y nacional (ciudadano). Lamentablemente se trata aún de un concepto por desarrollar.

Si nos preguntamos ahora hasta qué punto el reconocimiento de la ciudadanía plena $-\mathrm{o}$ de un cierto nivel de derechos básicos - es una condición suficiente para la integración, nos encontraremos, además, con que, por un lado, el reconocimiento de los derechos de ciudadanía no es suficiente para integrar a los grupos que se han visto previamente excluidos de una participación social plena (Palou, 2007). Y, por otro, el ejercicio de una ciudadanía activa no se puede limitar, de hecho, a los aspectos formales ${ }^{10}$.

\section{Ampliando la noción de ciudadanía}

Ante esto cabe plantearse una ciudadanía que vaya más allá de los aspectos formales, de la participación electoral. Una ciudadanía orientada a jugar un papel activo en la transformación de la propia realidad, de la más cercana; participando en la toma de decisiones de la gestión de lo público, de lo cercano, de aquello que afecta a todas las personas de una comunidad en cuanto vecinas (en las comunidades de vecinos, en los colegios, en las asociaciones, en los barrios....). Una ciudadanía, por tanto, empoderante.

Una ciudadanía local, que permitiría entender más fácilmente cómo todas las personas del vecindario -independientemente de su origen, del tiempo que lleve en la comunidad y de otras variables potencialmente segregadoras - comparten tareas, necesidades, deberes y derechos (De Lucas, 2005). Una ciudadanía, por tanto, inclusiva, plural e igualitaria, que permite sentir a todas y todos juntos, libres e iguales.

Se trata de evitar el anclaje de la ciudadanía en la nacionalidad y desplazarlo a la vecindad recurriendo a nociones como 'presencia' y 'ciudadanía' de facto $^{11}$, y recuperando la idea de ciudadanía como proceso, como forma de vida, en lugar de considerarla meramente como un status.

Sirva esta frase de Folgueiras (2004) para cerrar el artículo con una de las ideas centrales de la propuesta ciudadanista: "La participación ciudadana es un elemento generador de identidad cívica. La participación promueve la formación de vínculos cívicos entre las personas así como entre ellas y la comuni-

\footnotetext{
10 Este planteamiento está en línea con los más recientes enfoques sobre participación ciudadana orientados a complementar las formas de democracia representativa con formas de democracia directa o participativa. Al respecto puede consultarse, por ejemplo, el trabajo de Sola y Casellas (2004).

${ }^{11}$ Nociones utilizadas por Sassen (2003).
} 
dad en la que participan. Por tanto, se puede afirmar que las dinámicas participativas son generadoras de un tipo de identidad cívica que nada tiene que ver con la pertenencia a una comunidad prepolítica en la que la integración se alcanza por medio de la descendencia, la tradición y el lenguaje común, sino que es fruto del diálogo, las opiniones, el intercambio, etc., que se generan entre personas que participan en un mismo espacio".

\section{Bibliografía}

Cabezas, J. M. (2007) Los etnosistemas: Una nueva teoría para nuevas prácticas interculturales. En $V$ Congreso sobre la Inmigración en España "Migraciones y desarrollo humano". Valencia. [http:// http://www.adeit.uv.es/inmigracion2007]

Catep y Sembla (2006). Integración y Ciudadanía. Guía para aplicar la perspectiva de la gestión de la diversidad a los procesos de integración en el ámbito municipal. Ayuntamiento de Parla. [http://www.catep.coop/guiaic]

Cobo, R. (2006). Intervención ante la Mesa Técnica de Diversidad del Ayuntamiento de Parla. 2 de noviembre de 2006.

Cortina, A. (2004). Ética discursiva y educación en valores. En $X V$ Congreso Interamericano de Filosofía. Lima.

[http://www.pucp.edu.pe/eventos/congresos/filosofia/programa_general/miercoles/sesion 15 16.30/AdelaCortina.PDF]

De Bono, E. (1997). Seis sombreros para pensar. Granica. Barcelona.

De Lucas, J. (2005). La integración política como condición del modelo de integración. En Documentación Social, 139.

Delgado, M. (1999). Dinámicas identitarias y espacios públicos. Revista Cibod d'Afers Internacionals, 43-44.

Delgado, M. (2007). Intervención ante la Mesa Técnica de Diversidad del Ayuntamiento de Parla. 16 de noviembre de 2007.

Entzinger, H. y Biezeveld, R. (2003). Benchmarking in Immigrant Integration. European Research Centre on Migration and Ethnic Relations. Rotterdam.
FAAEE. (2003). Declaración del IX Congreso de Antropología de la Federación de Asociaciones de Antropología del Estado Español. En Quaderns de l'Institut Català d'Antropologia, 19.

Flecha, R. (2005). Teorías dialógicas en sociedades multiculturales. En Antonio Ariño Villarroya (coord.). Las encrucijadas de la diversidad cultural. Centro de Investigaciones Científicas. Madrid.

Folgueiras, P. (2004). De la tolerancia al reconocimiento mutuo: programa de formación para una ciudadanía activa e intercultural. En IV Congreso sobre la Inmigración en España. Universitat de Girona. Girona.

Franzé, A. Casellas, L. y Gregorio, G. (1999). Intervención social con población inmigrante: peculiaridades y dilemas. En Migraciones, 5.

Gandhi, M. (1921). English Learning. En Young India, 1 de junio de 1921.

Garreta, J. (2003). La integración sociocultural de las minorías étnicas (gitanos e inmigrantes). Anthropos. Barcelona.

Giner, S. (1997). Universalismo y relativismo. En Identidades y conflicto de valores. Diversidad y mutación social en el Mediterráneo. Icaria. Barcelona.

Gregorio, C. y Franzé, A. (1999). Intervención social con población inmigrante: esos 'otros' culturales. En Intervención Psicosocial, vol. 8, 2.

Martín, E. (2007). Intervención ante la Mesa Técnica de Diversidad del Ayuntamiento de Parla. 25 de enero de 2007.

Navarro, N. (2007) Entrevista a Najat El Hachmi.

http://www.gencat.net/salut/portal/cat/_notes/trans/ nachat.pdf.

Habermas, J. (1999). La inclusión del otro. Paidós. Barcelona, 1999.

Morokvasic, M. (1984). Birds of passage are also women. En International Migration Review, 18.

Pajares, M. (2005). La integración ciudadana. Una perspectiva para la inmigración. Icaria. Barcelona.

Palou, B. (2007). Las variables de la integración. En $V$ Congreso sobre la Inmigración en España "Migraciones y desarrollo humano". Valencia.

[http:// www.adeit.uv.es/inmigracion2007]

MTAS. (2007). Plan Estratégico de Ciudadanía e 
Integración 2007-2010. Ministerio de Trabajo y Asuntos Sociales.

PNUD. (2004). Informe sobre desarrollo humano 2004. La libertad cultural en el mundo diverso de hoy. Mundi Prensa. Madrid.

Sassen, S. (2003). Contrageografías de la globalización. Traficantes de Sueños. Madrid.

Sola, A. y Casellas, L. (2004). El papel de las administraciones locales en la participación ciudadana. En Intervención Psicosocial, vol.13, 2.

Stolcke, V. (1999). La nueva retórica de la exclusión en Europa. En Revista Internacional de Ciencias Sociales, 159.

Touraine, A. (1995). Minorías, pluriculturalismo e integración. El País, 12 de enero de 1995.

UE. (2000). Comunicación de la Comisión al Consejo y al Parlamento Europeo sobre una política comunitaria de migración. COM (2000) 757 final.
UE. (2004). Principios básicos comunes para las políticas de integración de los inmigrantes en la Unión Europea. Aprobados por el Consejo de la Unión Europea y los representantes de los Gobiernos de los Estados miembros en 19 de noviembre de 2004.

Uribe, J. M. (2007). Servicios sanitarios y demandas culturales: Diálogos interculturales. En $V$ Congreso sobre la Inmigración en España "Migraciones y desarrollo humano". Valencia. [http:// www.adeit.uv.es/inmigracion2007]

Villalobos, C. (2003). Los inmigrantes y la delincuencia en prensa. Una Imagen distorsionada. Grupo de Investigación en Comunicación y Cultura. Universidad de Sevilla.

Zubero, I. (2005). Especie humana y ciudadanía común: del sueño de la razón ilustrada al proyecto de la filantropía cosmopolita. En Documentación Social, $n^{\circ} 139$.

Manuscrito recibido: 01/06/2009

Revisión recibida: 15/06/2009

Manuscrito aceptado: 25/06/2009 